\title{
CARACTERIZAÇÃO DAS ULCERAS DE PRESSÃO EM IDOSOS HOSPITALIZADOS
}

\author{
Nágila Oliveira Discente do Curso de Graduação em Enfermagem na \\ Faculdade Independente do Nordeste.
}

\begin{abstract}
Luciana Araújo dos Reis
Fisioterapeuta, Mestre e Doutora em Ciências da Saúde/UFRN, Estágio Pós-doutoral em Saúde Coletiva/UFBA/ISC. Docente Adjunta da Universidade Estadual do Sudoeste da Bahia e Docente Titular da Faculdade Independente do Nordeste.
\end{abstract}

Endereço para correspondência: lucianauesb@yahoo.com.br

\begin{abstract}
Resumo
Objetivo: caracterizar as úlceras de pressão em idosos hospitalizados. Metodologia: trata-se de um estudo exploratório descritivo realizado em um hospital público do município de Vitória da Conquista/BA, com uma amostra de 40 idosos portadores de Úlceras de Pressão. Para coleta dos dados utilizou-se um questionário contendo questões sociodemográfica e de caracterização das ulceras, sendo os dados analisados de maneira descritiva por meio do Programa Estatístico SPSS versão 20.0. Resultados: constatou-se no presente estudo que houve uma maior distribuição de idosos com sexo feminino (43,6\%), casado (38,5\%), não alfabetizado $(61,5 \%)$ e aposentado $(46,2 \%)$, com média de idade de 73,10 $( \pm 9,31)$ anos. Dos 39 idosos avaliados, 100,0\% apresentaram Úlcera de Pressão; 61,5\% apresentaram problemas de saúde associados à presença de UP e 94,9\% relataram lesão cutânea prévia. A maioria dos idosos apresentaram úlceras localizadas no Coccix $(97,4 \%)$, com tempo de 10 dias $(33,3 \%)$, com quantidade referente a 1 (uma) úlcera $(97,4 \%)$ e infeccionadas $(66,7 \%)$. Quanto à avaliação dos fatores de risco observou-se que os de maior frequência foram: pontos de pressão $(28,2 \%)$, valores laboratoriais anormais $(28,2 \%)$ e presença de patôgenes Crônico-degenerativos $(17,9 \%)$. Conclusão: a maioria dos idosos apresentaram problemas de saúde associados à presença de úlceras infeccionadas e relataram lesão cutânea prévia. Verificou-se que os mesmos, apresentaram úlceras de pressão infeccionadas localizadas no cóccix com uma lesão cutânea prévia.
\end{abstract}

Palavras-chave: Cuidador; Úlcera de pressão; Idosos.

\section{PREVALENCE OF PRESSURE ULCERS IN ELDERLY INPATIENT AND THE ROLE OF CAREGIVER}

\begin{abstract}
Objective: To characterize the pressure ulcers in hospitalized elderly. Methodology: this is an exploratory study carried out at a public hospital in the city of Vitória da Conquista/BA, with a sample of 40 elderly patients with pressure ulcers. For data collection we used a questionnaire with sociodemographic and characterization of ulcers, and the data analyzed descriptively using the statistical program SPSS version 20.0. Results: It was found in this study that there was a greater distribution of elderly females (43.6\%), married (38.5\%), illiterate (61.5\%) and retired $(46.2 \%)$, with a mean age of $73.10( \pm 9.31)$ years. Of the 39 patients included, showed $100.0 \%$ Pressure Ulcer, $61.5 \%$ had health problems associated with the presence of UP and $94.9 \%$ reported previous skin injury. Most seniors presented ulcers located in the coccyx (97.4\%), with time 10 days (33.3\%), with much respect to one (1) ulcer $(97.4 \%)$ and infected $(66.7 \%)$ On the analysis of risk factors showed that the most frequent were: pressure points $(28.2 \%)$, abnormal laboratory values $(28.2 \%)$ and the presence of pathogens Chronic- degenerative (17.9\%). Conclusion: Most of the elderly had health problems associated with the presence of ulcers and infected skin lesion prior reported. It was found that they showed infected pressure ulcers located in the coccyx with a skin lesion in advance.
\end{abstract}

Keywords: Caregiver; Pressure ulcer; Seniors. 


\title{
PREVALENCIA DE ÚLCERAS POR PRESIÓN EN PACIENTES ANCIANOS Y EL PAPEL DEL CUIDADOR
}

\begin{abstract}
Resumen
Objetivo: Caracterizar las úlceras por presión en ancianos hospitalizados. Metodología: se trata de un estudio exploratorio realizado en un hospital público en la ciudad de Vitória da Conquista/BA, con una muestra de 40 pacientes ancianos con úlceras por presión. Para la recolección de datos se utilizó un cuestionario con variables sociodemográficas y la caracterización de las úlceras y los datos analizados descriptivamente utilizando el programa estadístico SPSS versión 20.0. Resultados: Se encontró en este estudio que hubo una mayor distribución de las mujeres de edad avanzada (43,6\%), casados $(38,5 \%)$, analfabetos $(61,5 \%)$ y jubilados $(46,2$ $\%)$, con una edad media de 73,10 $( \pm 9,31)$ años. De los 39 pacientes incluidos, mostró úlcera por presión 100.0 $\%, 61.5 \%$ tenían problemas de salud asociados con la presencia de la UP y el 94,9 \% reportado lesiones en la piel anterior. La mayoría de los adultos mayores presentan úlceras localizadas en el coxis $(97,4 \%)$, con un tiempo de 10 días $(33,3 \%)$, con mucho respeto a uno (1) úlcera $(97,4 \%)$ e infectados $(66,7 \%)$ En el análisis de los factores de riesgo mostró que las más frecuentes fueron: los puntos de presión $(28,2 \%)$, valores de laboratorio anormales $(28,2 \%)$ y la presencia de agentes patógenos crónico - degenerativa $(17,9 \%)$. Conclusión: La mayoría de las personas de edad tienen problemas de salud asociados con la presencia de úlceras y lesiones de la piel infectada antes descrito. Se encontró que mostraron las úlceras por presión infectadas situadas en el coxis con una lesión de la piel con antelación.
\end{abstract}

Palabras clave: Cuidador; Úlceras por presión; Las personas mayores.

\section{INTRODUÇÃO}

Envelhecer é um fenômeno natural dos seres humanos, desde o momento em que nascemos o processo se inicia. Este assunto passou a ser de muito interesse recentemente pelo mundo, onde o envelhecimento populacional tem despertado nos últimos anos preocupações com as necessidades desse grupo crescente.

Em países subdesenvolvidos como o Brasil a população acima dos 65 anos tem crescido de forma expressiva e sem as conquistas sociais de que necessita uma sociedade envelhecida. $\mathrm{Na}$ área de saúde se tornou um tema atual, principalmente no âmbito hospitalar, onde a demanda de atendimento a pacientes idosos tem sido expressiva pegando muitas unidades despreparadas, afetando diretamente o atendimento e a rotina dos trabalhadores diretamente envolvidos com o processo.

Segundo o Instituto Brasileiro de Geografia e Estatística/IBGE¹, no Brasil o número de pessoas com 60 anos ou mais superava o número de crianças menores de cinco anos em 17,9\%. Para o período de 2000 - 2050 estima-se que o número de idosos no país ultrapasse os 40 milhões.

Conforme Siqueira et $\mathrm{al}^{2}$, com o aumento da população na terceira idade no Brasil fazse necessário uma estruturação nos serviços e programas de saúde, para que possam atender de forma satisfatória esta demanda emergente. Estes utilizam o serviço hospitalar de maneira 
intensa que os demais grupos etários, envolvendo maiores custos, implicando num tratamento de duração mais prolongada e de recuperação mais lenta e complicada.

Atualmente, é de fundamental importância que o profissional interessado nesta área esteja atualizado nas peculiaridades anatômicas e funcionais do envelhecimento, sabendo discernir com máxima precisão os efeitos naturais deste processo (senescência) das alterações reduzidas pelas inúmeras afecções que pode acometer o idoso (senelidade). ${ }^{(3)}$

A úlcera por pressão é entendida como uma lesão cutânea ocasionada por uma pressão exercida em áreas de proeminência óssea, impedindo ou dificultando a perfusão tissular, tendo como consequência danos teciduais e até necrose. ${ }^{(3)}$

Portanto, acredita-se que o envelhecimento da pele poderá favorecer lesões do tipo úlceras por pressão. Por ser um problema comum e constante em indivíduos idosos hospitalizados, a combinação dos fatores de risco aliados à idade torna-se um problema de saúde pública que deve ser prevenido e acompanhado de perto, pela diversidade de consequências que podem surgir.

Em se tratando da pessoa idosa, o envelhecimento da pele é um dos aspectos que mais influenciam na aquisição de úlceras por pressão, pois sua pele, órgão mais exposto às agressões externas, possui funções primordiais relacionadas com a proteção, a termorregulação, a barreira contra microrganismos, à regeneração e a cicatrização de lesões.

O envelhecimento do sistema tegumentar deve ser compreendido em todas as suas fases, no intuito de melhorar a qualidade de vida do idoso hospitalizado e com dependência, pois será possível uma detecção precoce de lesões, traumas e outras patologias. Dessa forma, nesta etapa da vida, a pele passa por mudanças drásticas como redução do número de vasos sanguíneos, queda dos pêlos, diminuição dos pigmentos protetores como a melanina.

Segundo Warriner e Cárter ${ }^{(4)}$ no hospital as UP ocorrem frequentemente em pessoas com diversas morbilidades, especialmente as que estão perto do fim da vida, ainda que recebam bons cuidados.

Para Jaul ${ }^{(5)}$ a presença de uma úlcera constitui uma síndrome geriátrica composta por condições patológicas ligadas a diversos fatores. A imobilidade, deficiência nutricional e doenças crónicas, ao predispor o envelhecimento da pele da pessoa idosa, aumenta a vulnerabilidade para úlcera. $\mathrm{O}$ autor acrescenta que a avaliação e gestão de uma úlcera de pressão exigem uma abordagem global e multidisciplinar.

Sendo as UP evitáveis, medidas preventivas devem ser instituídas desde a admissão na instituição de saúde ou no domicílio aos doentes com déficit de mobilidade, uma vez que 
estas medidas podem evitar sofrimento e custos dispendiosos inerentes ao doente, a família e as instituições. ${ }^{(5)}$ Trinta e um estudos e 2.463 doentes foram incluídos numa Revisão Sistemática realizada na Inglaterra com o objetivo de identificar o impacto das úlceras de pressão e de seus tratamentos sobre a qualidade de vida dos idosos.

Os fatores de risco para úlcera por pressão devem ser corrigidos e acompanhados tais como o déficit nutricional, alterações dos exames laboratoriais, incontinências, medicamentos, umidade, fricção, pressão e cirurgias. A assistência de enfermagem deve abranger estes aspectos e os relacionados ao cliente como o emocional, psicológico, fisiológico e autoestima.

As úlceras têm um impacto significativo na qualidade de vida do doente com efeitos nocivos de ordem física, social, psicológica e de saúde em geral, além de causar ónus substancial ao portador desta lesão. Nesta perspectiva, o presente estudo tem por objetivo caracterizar as ulceras de pressão em idosos hospitalizados.

\section{METODOLOGIA}

Quanto à metodologia trata-se de um estudo Quantitativo-Descritivo: investigação empírica, com o objetivo de conferir hipóteses, delineamento de um problema, análise de um fato, avaliação de programa e isolamento de variáveis principais. ${ }^{(6)}$

O estudo foi realizado em um hospital público do município de Vitória da Conquista, BA. A amostra do estudo foi constituída por 40 idosos portadores de Úlceras de Pressão hospitalizados no período de 04 de abril a 24 de maio de 2013.

Como instrumento de pesquisa foi utilizado um roteiro contendo informações sócio demográficas, de saúde e referentes à caracterização das UP. Em atendimento a Resolução 466/12, para participar da pesquisa os idosos assinaram um Termo de Consentimento Livre e Esclarecido.

Inicialmente o projeto foi encaminhando ao Núcleo de Educação Permanente do referido hospital e após a sua autorização para coleta de dados o projeto foi submetido e aprovado no Comitê de Ética em Pesquisa da faculdade Independente do Nordeste. Em seguida teve início a coleta de dados.

A coleta de dados foi realizada pela própria autora da pesquisa em horários determinados pela equipe de Enfermagem de modo a não prejudica a rotina da unidade. 
Após a coleta os dados foram inseridos inicialmente uma planilha do Excel e em seguida transportados para uma planilha do Programa Estatístico SPSS versão 20.0, no qual foram realizadas análises estatísticas descritivas.

\section{RESULTADOS}

Constatou-se no presente estudo, segundo a Tabela 1,que houve uma maior distribuição de idosos com sexo feminino $(43,6 \%)$, casado $(38,5 \%)$, não alfabetizado $(61,5 \%)$ e aposentado (46,2\%), com média de idade de 73,10 ( $\pm 9,31)$ anos.

Tabela 1 - Distribuição das condições sócio-demográficas dos idosos. Vitória da Conquista/BA, 2013.

\begin{tabular}{lcc}
\hline & n & \% \\
\hline Sexo & 17 & 43,6 \\
Feminino & 22 & 56,4 \\
Masculino & & \\
Estado Civil & 15 & 38,5 \\
Casado (a) & 4 & 10,3 \\
Solteiro (a) & 14 & 35,9 \\
Viúvo (a) & 6 & 15,4 \\
Separado (a) & & \\
Escolaridade & 24 & 61,5 \\
Não alfabetizado & 15 & 38,5 \\
Alfabetizado & & \\
Profissão & 3 & 7,7 \\
Autônomo & 9 & 23,1 \\
Agricultor & 2 & 3,1 \\
Caminhoneiro & 18 & 46,2 \\
Aposentado & 5 & 12,8 \\
Dona de Casa & 2 & 5,1 \\
Doméstica & 39 & \\
\hline Total & & \\
\hline Fonte: Pesquisa & & \\
\hline & & \\
\hline
\end{tabular}

Fonte: Pesquisa de Campo, 2013. 
Dos 39 idosos avaliados, 100,0\% apresentaram Úlcera de Pressão; 61,5\% apresentaram problemas de saúde associados à presença de UP e 94,9\% relataram lesão cutânea prévia. A maioria dos idosos apresentaram úlceras localizadas no Coccix $(97,4 \%)$, com tempo de 10 dias $(33,3 \%)$, com quantidade referente a 1(uma) úlcera $(97,4 \%)$ e infeccionadas $(66,7 \%)$.

Tabela 2 - Distribuição dos idosos segundo as características das úlceras. Vitória da Conquista/BA, 2013

\begin{tabular}{lcc}
\hline & $\mathrm{n}$ & $\%$ \\
\hline Localização da Úlcera & 38 & 97,4 \\
Cóccix & 1 & 2,6 \\
Cóccix e Calcâneo & & \\
Infeccionada & 26 & 66,7 \\
Sim & 13 & 33,3 \\
Não & & \\
Quantidade & 38 & 97,4 \\
1 Úlcera & 1 & 2,6 \\
3 Úlceras & & 23,1 \\
Tempo da Úlcera & 9 & 33,3 \\
5 dias & 13 & 30,8 \\
10 dias & 12 & 12,8 \\
15 dias & 5 & 100,0 \\
Mais de 20 dias & 39 & \\
\hline Total & & \\
\hline
\end{tabular}

Fonte: Pesquisa de Campo, 2013.

Quanto à avaliação dos fatores de risco observou-se que os de maior frequência foram: pontos de pressão $(28,2 \%)$, valores laboratoriais anormais $(28,2 \%)$ e presença de patôgenes Crônico-degenerativos $(17,9 \%)$.

Existem outros agravantes no risco para aparecimento das úlceras por pressão, como a pressão exercida sobre as proeminências ósseas, cisalhamento, fricção e umidade excessiva. De todos esses fatores, pode-se destacar como mais presente e o principal agente causador da lesão, a pressão exercida nos tecidos moles entre as proeminências ósseas. 
Tabela 3 - Distribuição dos idosos segundo os fatores de risco. Vitória da Conquista/BA, 2013

\begin{tabular}{lcc}
\hline & $\mathbf{n}$ & $\mathbf{\%}$ \\
\hline Fatores de Risco & 1 & 2,6 \\
Estado Nutricional Deficitário & 11 & 28,2 \\
Pontos de Pressão & 11 & 28,2 \\
Valores Laboratoriais Anormais & 7 & 17,9 \\
Patôgenes Crônico-degenerativos & 4 & 10,3 \\
Integridade de Tíssulas Prejudicadas & 5 & 12,8 \\
Incontinência Urinária e Fecal & 39 & 100,0 \\
\hline Total & & \\
\hline
\end{tabular}

Fonte: Pesquisa de Campo, 2013.

\section{DISCUSSÃO}

A hospitalização em idosos envolve uma série de questões como acesso aos serviços de saúde, sexo, idade, patologias, tempo de permanência nos hospitais e complicações, dentre elas as úlceras por pressão. Por essas razões, as doenças degenerativas podem ser detectadas mais precocemente nas mulheres e, portanto, contribuindo para um tratamento efetivo e prognóstico melhor.

O nível de escolaridade e estado civil são importantes para averiguar se o aspecto educativo, a vida social e aspectos emocionais que podem influenciar diretamente nos indicadores de saúde da população idosa e, portanto, em sua tendência maior ou menor para o adoecimento e internação.

De acordo com os resultados apresentados, dentre os participantes da pesquisa, houve uma maior frequência de idosos casados, indicando que a maioria dos pacientes idosos internados no hospital selecionado para o estudo, convive com um companheiro ou companheira.

A caracterização do estado civil da população idosa em estudo manifesta que a convivência com os cônjuges ainda é bem frequente e valorizada pela sociedade. Além disso, os parceiros ou parceiras são as pessoas que geralmente cuidam da saúde de seus maridos e esposas e demonstram preocupação em procurar assistência médica, especialmente as mulheres. Confirma-se, então, a necessidade dos idosos, especialmente os já em idade 
avançada e portadores de patologias crônico-degenerativas de acompanhamento contínuo pela equipe de saúde, tendo, portanto o cônjuge uma função ímpar no tratamento e recuperação.

Quanto à escolaridade, verifica-se que a maioria dos idosos é analfabeta. A questão da escolaridade interfere diretamente no nível de saúde da população e na sua capacidade para adquirir um estilo saudável de vida, bem como participar ativamente do tratamento indicado à sua patologia.

Alves e Rodrigues ${ }^{(7)}$ concordam com diversos autores que o envelhecimento saudável é possível graças à combinação de variados fatores como a idade, sexo, o estado conjugal, a educação, as doenças crônicas e a capacidade funcional. Ainda de acordo com esses autores, aqueles idosos com níveis educacionais mais baixos podem tecer expectativas mais baixas em relação ao seu estado de saúde. Esse aspecto pode interferir na capacidade do idoso de adquirir um comportamento saudável, devido ao seu nível de escolaridade.

A pesquisa mostra que a maioria das UP estão localizada no Cóccix, afetando os pacientes e que as mesmas, estão infeccionadas. Segundo Marini ${ }^{(8)}$ determinados pontos do corpo, principalmente as proeminências ósseas, concentram pressões maiores, motivo pelo qual eles são os mais acometidos pelas úlceras de pressão, é o caso do cóccix. Para a autora ${ }^{(8)}$ no que diz respeito à localização das úlceras essa região é a mais acometida de 29,5\% a 35,8\% de acordo com sua pesquisa.

Resultados semelhantes aos nossos são descritos em estudos realizados por Blanes ${ }^{9}$ e Fernandes ${ }^{10}$ que identificaram fatores como: fricção e cisalhamento, deficiência nutricional, diminuição da mobilidade, diminuição da percepção sensorial, aumento da umidade, como sendo de risco nos pacientes com UP no cóccix.

A avaliação do paciente deve abranger diversos aspectos que incluem os fatores de risco para a formação das úlceras por pressão no cóccix. ${ }^{(9-10)}$

Neste sentido, os pacientes idosos estão especialmente em risco maior de adquirir úlceras por pressão no cóccix, pela questão da idade, envelhecimento dos sistemas orgânicos, ocorrência de doenças crônico-degenerativas e outras patologias crônicas, problemas de imunidade e fragilidade do sistema tegumentar. Por essas razões, considera-se necessário conhecer algumas nuances relacionada ao processo de envelhecimento do organismo humano, principalmente, do sistema tegumentar.

Outro fator observado na pesquisa é que o idoso apresenta uma maior propensão para o aparecimento de doenças crónicas que predispõem ao desenvolvimento de úlceras. Doenças como a diabetes, insuficiência renal e vascular, doenças oncológicas e ainda, estados de 
desnutrição que reduzem a capacidade de síntese do colágeno e de outros elementos da cicatrização, aumentam a suscetibilidade para as úlceras de pressão.

Quanto a UP percebemos que existe uma diversidade de fatores intrínsecos que resulta na predisposição para o desenvolvimento das mesmas. A idade surge como um fator de grande importância e não passível de modificação. O envelhecimento é acompanhado por uma redução dos processos metabólicos, da velocidade de cicatrização e da vascularização, da espessura e elasticidade da pele e diminuição qualitativa e quantitativa do colagénio, pelo que feridas semelhantes cicatrizam de forma mais rápida na criança em comparação com o idoso.

Outro fator observado na pesquisa é que oidoso apresenta uma maior propensão para o aparecimento de doenças crónicas que predispõem ao desenvolvimento de úlceras. Doenças como a diabetes, insuficiência renal e vascular, doenças oncológicas e ainda, estados de desnutrição que reduzem a capacidade de síntese do colágeno e de outros elementos da cicatrização, aumentam a suscetibilidade para as úlceras de pressão.

Observamos que as situações que podem levar a uma mobilidade reduzida são diversas e podemos destacar as lesões medulares ou doenças neurológicas associadas a paralisia e perda sensorial, o coma, sedação excessiva, demência avançada, doentes geriátricos ou que são submetidos a grande cirurgia. A incapacidade de mover-se e a redução da frequência na alternância de decúbitos pode afetar a capacidade de aliviar a pressão, predispondo ainda à fricção e às forças de torção se o indivíduo estiver acamado ou ainda confinado à cadeira. Para além disso, uma diminuição da mobilidade provoca estase na circulação periférica, nomeadamente nos membros inferiores.

Os doentes desnutridos, com deficiências proteicas e vitamínicas, estão mais sujeitos ao desenvolvimento de úlceras de pressão e apresentam uma dificuldade acrescida no processo de cicatrização das úlceras existentes. A presença de exsudado contribui para a hipoproteinémia uma vez que, em úlcera de pressão extensa, podem ser desperdiçadas mais de $30 \mathrm{~g}$ de proteínas por dia (Bryant, 2000). As proteínas e vitamina C, além de desempenharem outras funções, contribuem para a síntese de colágeno, essencial para a cicatrização dos tecidos e para a resposta imunológica.

De acordo com a literatura apontada um estado nutricional deficiente e a desidratação estão associados à ocorrência de úlceras de pressão, uma vez que conduzem a uma mobilidade reduzida, à apatia e depressão e à diminuição da imunocompetência. Indivíduos que apresentam distúrbios nutricionais estão mais suscetíveis a complicações, internamentos mais 
prolongados e necessidade de repouso no leito por tempo acrescido, todos fatores que aumentam o risco para UP.

Cada uma dessas condições necessita de uma avaliação clínica do enfermeiro para a criação de um plano de prevenção para esse tipo de lesão, de acordo com as particularidades de cada cliente. Para que isso aconteça, o profissional deve lançar mão dos conhecimentos concernentes às úlceras por pressão e de como essas lesões afetam as pessoas em idade avançada.

\section{CONCLUSÃO}

Observou-se no presente estudo que houve uma maior distribuição de idosos com sexo feminino, casado, não alfabetizado e aposentado. Todos os idosos avaliados apresentaram úlceras de pressão, sendo que a maioria apresentaram problemas de saúde associados à presença de úlceras infeccionadas e relataram lesão cutânea prévia. A localização mais frequente de úlceras foi o Coccix, o tempo de internamento foi de 10 dias, e a quantidade referente a 1 (uma).

As úlceras por pressão revelam-se como problemas de grande magnitude, especialmente dentro das instituições hospitalares. São complicações iminentes que podem ocorrer em clientes hospitalizados, principalmente naqueles com idade avançada.

Neste sentido, o envelhecimento traz consigo dificuldades e desafios a serem superados por cada ser humano, pois implica mudanças corporais, no estilo de vida, nas atividades da vida diária e convivência com doenças e algumas limitações. A pele é um dos órgãos que mais sofrem com o envelhecimento, perde umidade, elasticidade, ou seja, perde com o passar dos anos a proteção natural contra agressões externas como as feridas e traumatismos. Por essas razões os idosos estão mais expostos do que a maioria das pessoas mais jovens ao desenvolvimento de lesões como as úlceras por pressão, aliado ao fato de também estarem expostos a alguns fatores de risco relacionados às úlceras.

Os problemas mencionados são considerados elementos que podem acelerar o aparecimento das úlceras por pressão, e muitos deles ocorrem, em sua maioria, no momento da hospitalização ou em patologias degenerativas que provocam imobilidade ou demências na pessoa idosa.

Neste estudo, percebemos a importância do assunto em questão e a importância do aprofundamento no mesmo, a fim de conhecermos as várias formas de prevenção, tratamento, 
além de identificar os fatores de riscos, diagnosticando seu estágio inicial a fim de atender de melhor forma o idoso.

\section{REFERÊNCIAS}

1. IBGE. Censo demográfico, microdados da amostra. Rio de Janeiro: IBGE; 2004.

2. Siqueira FV et al. Prevalência de quedas emidosos e fatores associados. Rev. Saúde Pública. 2007;41(5).

3. Papaléo Netto, M Finitude: hospital-fronteira. In: Py L, organizador. Finitude: uma proposta para reflexão e prática em gerontologia. Rio de Janeiro (RJ): Ed. NAU; 2007.

4. Warriner RA, Carter MJ. O estado atual das evidências protocolos baseados no tratamento de feridas. 2011 [ acesso em 2011 mar]. Disponível em:

<www.ncbi.nlm.nih.gov/pubmed/21200285>.

5. Jaul E. Assessment and management of pressure ulcers in the elderly: current strategies. Drugs Aging. 2010;27(4):311-25.

6. Marconi MDA, Lakatos EM. Técnicas de pesquisa: planejamento e execução de pesquisas, amostragens e técnicas de pesquisas, elaboração, análise e interpretação dedados. $3^{\mathrm{a}}$ ed. São Paulo: Atlas; 1996.

7. Alves LC, Rodrigues RN. Determinantes da autopercepção de saúde entre idosos do Município de São Paulo, Brasil. Rev. Panam. Salud Publica. 2005;17(5-6).

8. Marini, MFV. Úlceras de Pressão. Rio de Janeiro, Koogan; 2006.

9. Blanes L, Duarte IS, Calil JA, Ferreira LM. Avaliação clínica e epidemiológica das úlceras por pressão em pacientes internados no Hospital São Paulo. Rev. Ass. Med. Bras. 2004; 50(2):182-7.

10 Fernandes NCS, Torres GV. Ulcers of pressure in patients of intensive therapy unit: incidence and association of risk factors. The FIEP bulletin. 2006;76(2):55-8. 